\title{
Composition analysis and minimal treatments to solubilize polysaccharides from the brown seaweed Laminaria digitata for microbial growth of thermophiles
}

\author{
Leila Allahgholi ${ }^{1}$ - Roya R. R. Sardari ${ }^{1}$ - Sigrid Hakvåg ${ }^{2}$ • Kazi Z. G. Ara ${ }^{1}$ • \\ Thordis Kristjansdottir ${ }^{3}$. Inga Marie Aasen ${ }^{4}$. Olafur H. Fridjonsson ${ }^{3}$. \\ Trygve Brautaset $^{2}$. Gudmundur Oli Hreggvidsson ${ }^{3,5}$ • Eva Nordberg Karlsson ${ }^{1}$
}

Received: 27 September 2019 / Revised and accepted: 10 March 2020 / Published online: 30 March 2020

(C) The Author(s) 2020

\begin{abstract}
Brown macroalgae (Phaeophyta) hold high potential as feedstock for biorefineries due to high biomass productivity and carbohydrate content. They are, however, a challenging, unconventional feedstock for microbial refining and several processing problems need to be solved to make them a viable option. Pre-treatment is necessary to enhance accessibility and solubility of the biomass components but should be minimal and mild to assure sustainable and cost-effective processing. Here, two routes to pre-treatLaminaria digitata to release polysaccharides were investigated: hot water pre-treatment by autoclaving $\left(121{ }^{\circ} \mathrm{C}, 20 \mathrm{~min}\right.$ or $\left.60 \mathrm{~min}\right)$ and a two-step extraction with mild acid $(0.1 \mathrm{M} \mathrm{HCl})$ followed by alkaline treatment. Hot water pre-treatment resulted in partial extraction of a mixture of polysaccharides consisting of alginate, fucoidan and laminarin. After mild acid pre-treatment, alginate was found in the remaining insoluble residues and was extracted in a second step via alkaline treatment using $\mathrm{Na}_{2} \mathrm{CO}_{3}(0.15 \mathrm{M})$ at $80{ }^{\circ} \mathrm{C}$ and $\mathrm{CaCl}_{2}(10 \%)$ for the precipitation. In addition to carbohydrates, a fraction of other components such as proteins, phenolic compounds, minerals and trace elements was detected in the extracts. Cultivation of the thermophilic bacterial strains Rhodothermus marinus DSM 16675 and Bacillus methanolicus MGA3 (ATCC 53907) in media supplemented with the respective extracts resulted in growth of both strains, indicating that they were able to utilize the available carbon source for growth. $R$. marinus displayed the highest cell density in the medium containing the extract from acid pre-treatment, whereas B. methanolicus growth was highest with the extract from hot water pre-treatment.
\end{abstract}

Keywords Laminaria digitata . Mild physicochemical pre-treatment - Carbohydrate extraction $\cdot$ Rhodothermus marinus . Bacillus methanolicus

Leila Allahgholi

leila.allahgholi@biotek.lu.se

1 Department of Chemistry, Division of Biotechnology, Lund University, P.O. Box 124, 22100 Lund, Sweden

2 Department of Biotechnology and Food Science, NTNU, NO-7465 Trondheim, Norway

3 Matís, Vinlandsleid 12, 113, , Reykjavik, Iceland

4 SINTEF Industry, P.O. Box 4760 Torgarden, NO-7465 Trondheim, Norway

5 University of Iceland, Sæmundargata 2, 101, Ssn: 600169-2039 Reykjavík, Iceland

\section{Introduction}

Shortage of fossil-based resources and accumulation of greenhouse gases have increased interest in utilization of alternative renewable and sustainable resources such as marine biomass (Hannon et al. 2010). Industrial biotechnology uses large-scale fermentation of microorganisms growing on sugar-based raw materials requiring use of cultivable land and is therefore in unfavourable competition with food production. Marine macroalgae (red, green and brown algae), more commonly called seaweeds, represent an alternative renewable and sustainable biomass due to their high growth rate, high carbohydrate content and favourable composition of other components such as minerals, proteins and bioactive compounds. Moreover, seaweed cultivation will not compete with agricultural crops for use of 
arable land (Fernand et al. 2017). These properties of macroalgae have resulted in a surge of interest for this biomass as raw material in the production of energy, biofuels and high value-added chemicals (Chen et al. 2015).

The brown macroalga Laminaria digitata is a carbohydraterich biomass including alginate, fucoidan, laminarin and mannitol with seasonal variation in concentration. Alginate is a structural carbohydrate available in the cell wall of the seaweed and makes up 25 to $40 \%$ of the seaweed dry weight (Qin 2008). It is a linear polymer composed of $(1,4)$ linked $\beta$-D-mannuronic acid (M) and $\alpha$-L-guluronic acid (G) monomers. The $\mathrm{M} / \mathrm{G}$ ratio determines the rheological properties of alginate (Wu et al. 2014). Alginate is widely utilized in various industries due to its thickening, gelling and colloidal properties (Vauchel et al. 2008b; Lee and Mooney 2012). Fucoidans are branched homo- and heterosulphated polysaccharides of L-fucose units (Sardari and Karlsson 2018). Laminarin and mannitol are storage carbohydrates in macroalgae ranging from 1 to $25 \%$ and 3 to $20 \%$ of the seaweed dry weight, respectively (Adams et al. 2011). Laminarin is a $\beta-(1,3)$ glucan chain with occasional $\beta-(1,6)$ branching or linking (Rioux et al. 2007), while mannitol is the alcohol form of mannose. In addition, $L$. digitata also contains proteins, heavy metals, minerals and bioactive compounds (Schiener et al. 2015), and all these components have application potential in food and feed, biomedical and pharmaceutical industries (Martins et al. 2011; Saha and Racine 2011; Lee and Mooney 2012; Jönsson et al. 2020).

Until now, L. digitata has not been regarded as a favourable renewable source for energy production due to its high water content and significant amount of ash, compared with terrestrial biomass (John et al. 2014). Still, it is widely utilized for industrial extraction of alginate, as well as in cosmetic products (Bedoux et al. 2014) and fertilizers (Thorsen et al. 2010) and for extraction of single compounds for food and feed (Mæhre et al. 2014). There is now a considerable interest in utilizing seaweed extracts as raw materials for microbial cultivations in industrial biotechnology, and therefore intensive research is ongoing to find sustainable methods for preparing feedstock extracts for such applications.

While the potential of thermophilic enzymes has been recognized for a long time, thermophilic bacteria as bioconversion organisms have received less attention. Bioconversions, requiring cultivation and production of metabolites, have still mainly targeted mesophilic microorganisms that are easily cultivated and engineered. Many of these mesophiles are well proven using monosaccharides e.g. glucose as the prime carbon source, but they are far less suitable for other types of carbohydrate substrates (such as polysaccharides and sugar alcohols) derived from next-generation feedstocks. Both microbial species selected here (Rhodothermus marinus and Bacillus methanolicus) can grow at elevated temperatures as bioconversion organisms. The ability to grow at high temperatures in bioreactors facilitates extraction of volatile products, reduces the costs of cooling, distillation and extraction and prevents contamination of spoilage bacteria. Thermophiles are also optimal for many industrial bioconversion processes involving heterogeneous and viscous polysaccharides such as alginate. High temperature increases their solubility, leads to reduced viscosity of fermentation broths and facilitates enzymatic access (Hreggvidsson et al. 2015).

Rhodothermus marinus is a Gram-negative, obligate aerobic, thermophilic and halophilic bacterium (Alfredsson et al. 1988) and belongs to phylum Bacteroidetes (Bjornsdottir et al. 2006). This bacterium can utilize diverse carbon sources (Alfredsson et al. 1988) for growth, and its genome has genes putatively encoding enzymes required for complete degradation of several marine polysaccharides. The Gram-positive bacterium Bacillus methanolicus is a moderate thermophile. It is an aerobic facultative methylotroph and can utilize a few single carbon sources, including mannitol, for growth (Schendel et al. 1990; Arfman et al. 1992; López et al. 2019). Growth of B. methanolicus in $2 \% \mathrm{NaCl}$ and adaptation to rapid growth in seawater-based media has been described previously (Arfman et al. 1992; Komives et al. 2005). The selection of an appropriate production organism should be based on its physiological properties, including its "metabolic capacity" i.e. its potential to use substrates available in the feedstock as well as its potential to produce products of interest. The two bacterial species selected for this study represent highly different, but complementing, highly relevant substrate utilization profiles for the feedstock, and also both microbes produce products of interest. $R$. marinus has the capacity to produce exopolysaccharides (Sardari et al. 2017) and carotenoids (Ron et al. 2018) and for example B. methanolicus has been shown to produce cadaverine (Naerdal et al. 2015).

The purpose of this work was to study the effect of minimal, mild pre-treatment processes (hot water and mild acid) on milled biomass from $L$. digitata. Both soluble and insoluble fractions were analysed after the pre-treatment to investigate release of the major seaweed components, with special emphasis on the carbohydrates. In addition, the ability of the two industrial biotechnology-relevant thermophilic bacteria, $R$. marinus DSM 16675 and B. methanolicus MGA3 (ATCC53907), to utilize the marine carbon sources was evaluated by using pure carbohydrates and seaweed extracts in cultivations of the bacteria.

\section{Materials and methods}

\section{Biological materials and chemicals}

The seaweed was harvested in Breiðafjörður located in west of Iceland and dried and milled in the company Thorverk hf (Reykhólar, Iceland). All chemicals were from Sigma Aldrich unless otherwise specified. Guluronic acid was from 
Chemos (Germany), gallic acid and $\mathrm{NaOH}(50 \%)$ were from Merck (Germany) and ethanol was from Solveco (Sweden).

\section{Seaweed biomass}

Two batches of dried seaweed Laminaria digitata, (fine powder (LAM 50) and coarse powder (LAM 50/20)) were received from Thorverk hf. The two batches represent wild biomass, harvested in the period of January to early April at a depth of 2-11 $\mathrm{m}$ with the highest density at $6 \mathrm{~m}$ depth. The sites are harvested every 4 years by cutting the stem of the seaweed above the holdfast. Prior to milling, the seaweed is dried in a highly specialized band dryer that uses large quantities of air heated up to $85{ }^{\circ} \mathrm{C}$ by hot geothermal water $\left(120^{\circ} \mathrm{C}\right)$ in heat exchangers. The heat during the drying eliminates spoilage bacteria and other potentially harmful microorganisms.

\section{Mild acid pre-treatment}

The seaweed powder was mixed with $0.1 \mathrm{M} \mathrm{HCl}$ using a ratio of 1:10 (weight $(\mathrm{g})$ /volume $(\mathrm{mL})$ ) in an Erlenmeyer flask of appropriate volume for the scale of the experiment. The flask was covered and incubated at room temperature and $160 \mathrm{rpm}$ shaking for $2 \mathrm{~h}$ followed by $2 \mathrm{~h}$ incubation at $65^{\circ} \mathrm{C}$ and $160 \mathrm{rpm}$ shaking. The soluble fraction was collected after centrifuging at $3800 \times g$ for $10 \mathrm{~min}$ (Sigma 3-16PK centrifuge, Germany). The soluble and insoluble fractions were freeze dried (Devillé et al. 2004) and used for further experiments.

\section{Hot water pre-treatment}

The seaweed powder was mixed with distilled water using a ratio of 1:10 (weight $(\mathrm{g}) /$ volume $(\mathrm{mL})$ ). The mixture was covered and autoclaved for 20 or $60 \mathrm{~min}$ at $121^{\circ} \mathrm{C}$. After cooling, the insoluble fraction was removed by centrifuging at $3800 \times g$ for $10 \mathrm{~min}$ (Sigma 3-16PK centrifuge). The extract and solid remaining residues were freeze dried and used for further analysis (Obata et al. 2015).

\section{Extraction of alginates from the remaining solid residues of the acid pre-treated seaweed powder}

An amount of $0.50 \mathrm{~g}$ of freeze-dried acid-treated seaweed was mixed with $49.50 \mathrm{~g}$ of extraction solutions, either $\mathrm{Na}_{2} \mathrm{CO}_{3}$ $(0.15 \mathrm{M})$ or $\mathrm{NaOH}(0.3 \mathrm{M})$ (Fig. 1). The mixture was incubated at $80{ }^{\circ} \mathrm{C}$ in a water bath (Lauda E100, Lauda-Brinkman, USA) for $2 \mathrm{~h}$ with stirring. The supernatant, containing sodium alginate, was collected by centrifugation at $4000 \times g$ and $20{ }^{\circ} \mathrm{C}$ for $30 \mathrm{~min}$, and the resulting pellet was washed by adding $45 \mathrm{~mL}$ of distilled water, vortexing and centrifugation at $4000 \times \mathrm{g}$ for $10 \mathrm{~min}$. The pellet was dried at $50{ }^{\circ} \mathrm{C}$ for $72 \mathrm{~h}$.
To isolate alginate, $30 \mathrm{~mL}$ of either ethanol $(99.50 \%)$ or $\mathrm{CaCl}_{2}(10 \%)$ was added to the collected supernatant and incubated at $4{ }^{\circ} \mathrm{C}$ for $24 \mathrm{~h}$. The precipitated calcium alginate was separated via centrifugation at $4000 \times g$ and $20^{\circ} \mathrm{C}$ for $30 \mathrm{~min}$. In order to convert calcium alginate to alginic acid, the resulting pellet was mixed with $40 \mathrm{~mL}$ of washing solutions including $\mathrm{HCl}(1 \mathrm{M}), \mathrm{HCl}(0.01 \mathrm{M})$ and ethanol $50 \%$, individually, vortexed and centrifuged at $4000 \times g$ for $10 \mathrm{~min}$. The washing step was done twice with each washing solution. The resulting alginic acid was dried at $50{ }^{\circ} \mathrm{C}$ for $72 \mathrm{~h}$ (McHugh 1987; Vauchel et al. 2008a; Kadam et al. 2015; Sterner and Edlund 2016). All assays were done in duplicates, and alginate recovery was calculated using the following equation (Eq. (1)) and expressed in \%.

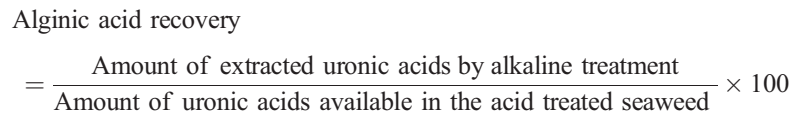

\section{Shake flask cultivation of Rhodothermus marinus DSM 16675}

A minimal medium was prepared using the RSNO 1599 medium recipe containing $1 \%(\mathrm{w} / \mathrm{v}) \mathrm{NaCl}$ explained by Blücher et al. (2000) with some modification. In the modified medium, L-glutamine, L-asparagine and iron citrate were omitted and $50 \mathrm{~mL}$ phosphate solution (containing $\mathrm{KH}_{2} \mathrm{PO}_{4}$ (27.22 $\left.\mathrm{g} \mathrm{L}^{-1}\right), \mathrm{Na}_{2} \mathrm{HPO}_{4}\left(28.39 \mathrm{~g} \mathrm{~L}^{-1}\right)$ ) was added (unpublished data). The $\mathrm{pH}$ was adjusted to 7.2 using $1 \mathrm{M} \mathrm{NaOH}$ before cultivation.

Commercial alginate, laminarin, glucose and the soluble fractions obtained from the pre-treatment of $L$. digitata were used as the respective carbon source. Twenty-five millilitres of the medium containing one type of the carbon sources were prepared in a baffled Erlenmeyer flask. Fresh inoculum (10\%) was added, and the flasks were incubated at $65{ }^{\circ} \mathrm{C}$ and $200 \mathrm{rpm}$ shaking for $24 \mathrm{~h}$. The cell growth was monitored by measuring the optical density (OD) at $620 \mathrm{~nm}$ at the beginning and after $24 \mathrm{~h}$ growth using a spectrophotometer (Ultrospec 1000 UV/VISIBLE, Pharmacia BioTek, England, and Novaspec III+, Biochrom, Harvard Bioscience Inc.) for alginate cultivations.

\section{Cultivation of Bacillus methanolicus}

The wild type strain Bacillus methanolicus MGA3 (ATCC 53907) was used in growth experiments. The strain was cultivated at $50{ }^{\circ} \mathrm{C}$ in $\mathrm{Man}_{10}$ medium, which is defined $\mathrm{MVcM}$ minimal medium that contains $1 \mathrm{mM} \mathrm{MgSO}_{4}$, high-salt buffer, vitamins, trace metals and $10 \mathrm{~g} \mathrm{~L}^{-1}$ mannitol as previously described (Brautaset et al. 2004; Jakobsen et al. 2006). Here, $\mathrm{Man}_{4.5}$ and $\mathrm{Man}_{2.5}$ corresponds to MVcM minimal medium 


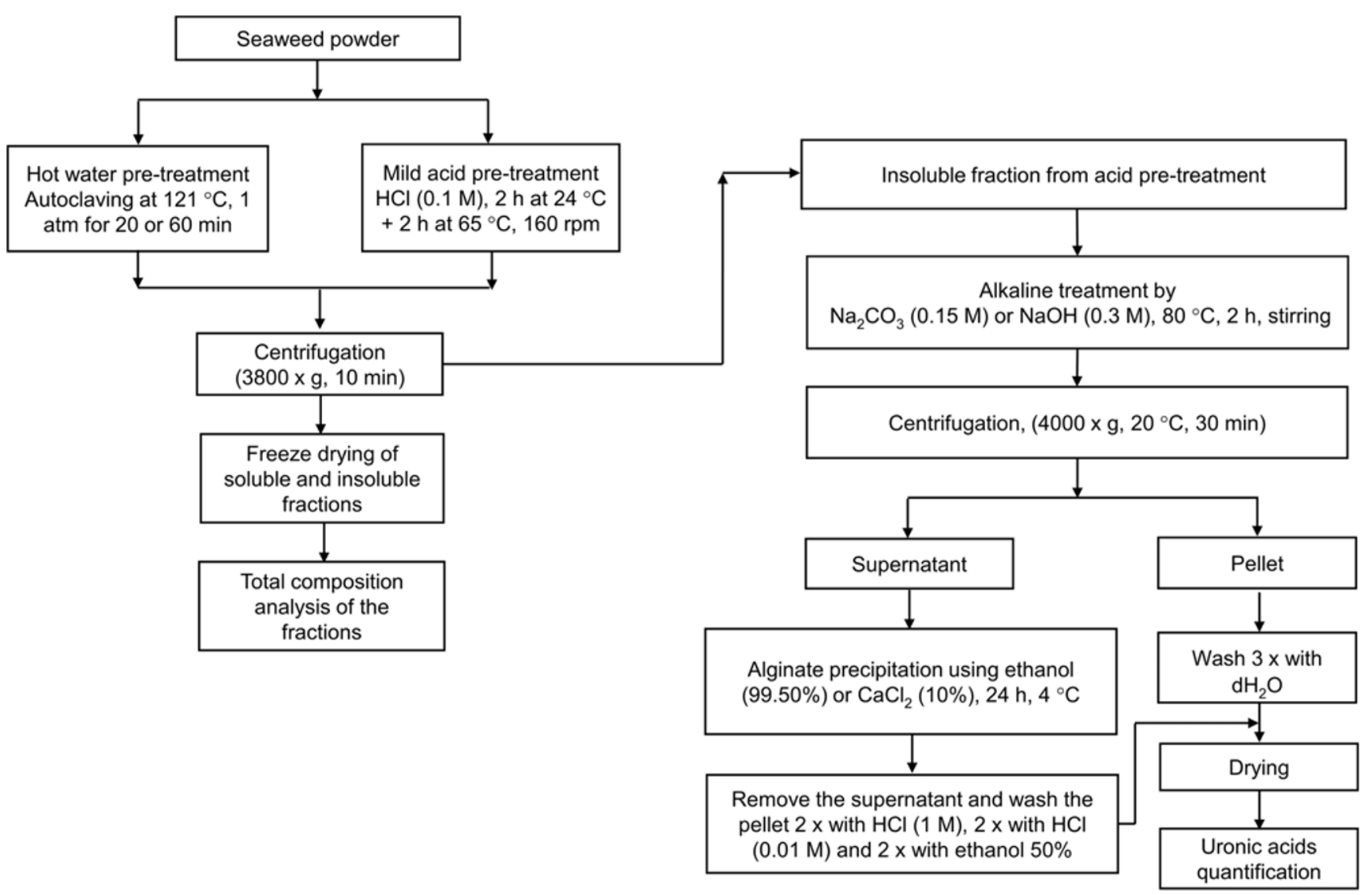

Fig. 1 Pre-treatment flowchart of L. digitata

with 4.5 and $2.5 \mathrm{~g} \mathrm{~L}^{-1}$ mannitol, respectively. Medium containing extracts of $L$. digitata was prepared with the same minimal medium, replacing mannitol with the extracts $(25$, 50 or $75 \%(\mathrm{v} / \mathrm{v})$ corresponding to approximately $1.4,2.8$ and $4.2 \mathrm{~g} \mathrm{~L}^{-1}$ respectively), as also described for extracts of Saccharina latissima in Hakvåg et., submitted for publication. The extracts were $\mathrm{pH}$-adjusted and autoclaved prior to mixing with the minimal medium. The $\mathrm{pH}$ was re-adjusted to $\mathrm{pH} 7.2$ with $1 \mathrm{M} \mathrm{NaOH}$ after mixing of minimal medium and the extracts, before pelleting of insoluble material by centrifugation at $7100 \times g$ for $10 \mathrm{~min}$. Conductivity was measured before and after centrifugation. The resulting supernatant was used as growth medium in the cultivations. Where noted, mannitol was added to a final concentration of in total $8.1 \mathrm{~g} \mathrm{~L}^{-1}$ for all cultures, to ensure a surplus of the available carbon source. The amount of mannitol added was determined based on the mannitol content of the extract (mild acid or hot water pretreated $L$. digitata).

Growth of B. methanolicus in deep well-plates(Greiner Bio-One $)(700 \mu \mathrm{L})$ or $250 \mathrm{~mL}$ baffled shake flasks $(40 \mathrm{~mL})$ was performed at 900 or $200 \mathrm{rpm}$, respectively, and monitored by measuring the $\mathrm{OD}_{600}$. A total of $100 \mu \mathrm{L}$ of culture from cryo-vials was used to inoculate precultures with $50 \mathrm{~mL}$ $\mathrm{Man}_{10}$ medium as previously described (Jakobsen et al. 2006). The cells were grown to an $\mathrm{OD}_{600}$ of 0.5 to 1.5 , pelleted and resuspended in fresh and pre-warmed medium, before inoculation to $\mathrm{OD}_{600}=0.1$ in fresh medium for growth analyses. Growth was monitored in shake flasks by measuring $\mathrm{OD}_{600}$ for 20-24 h (Unicam Helios Epsilon). Final $\mathrm{OD}_{600}$ was measured after 20-24 h of growth in deep well-plates (Spectramax Plus 384). All cultivations were performed in triplicates.

\section{Analytical methods}

\section{Ash content}

Ash content was measured after combusting the moisture free powder at $550{ }^{\circ} \mathrm{C}$ for $10 \mathrm{~h}$ in a furnace (Sluiter et al. 2008a). All measurements were carried out in triplicates, and quantification was done gravimetrically.

\section{Protein content}

The amount of protein was estimated by quantifying the nitrogen content of the seaweed via Dumas method using an elemental analyser (Flash EA 1112, Thermo Fisher Scientific, USA). Twenty-five milligam of the seaweed powder was weighted into a tin container and subjected to 
combustion at round $900-1000{ }^{\circ} \mathrm{C}$ in the presence of oxygen. Resulting nitrogen oxide was quantitatively converted to $\mathrm{N}_{2}$ in a reduction chamber containing copper at $650^{\circ} \mathrm{C}$, where other volatile products of combustion are either trapped or separated. Finally, the nitrogen gas was measured using a thermal conductivity detector. Asparagine was used for the calibration. Protein content was calculated with the nitrogen-to-protein conversion factor of 5 (Angell et al. 2016).

\section{Total phenolic content}

Twenty milliliter of distilled water was added to $0.2 \mathrm{~g}$ of the algae powder in a screw-cap glass tube with an aluminium liner. Extraction was carried out through the incubation of the mixture in a water bath at $70{ }^{\circ} \mathrm{C}$ for $1 \mathrm{~h}$, while the mixture was continuously mixed with a magnetic stirrer. Afterwards, the mixture was cooled to room temperature and centrifuged at $3800 \times g$ for $10 \mathrm{~min}$ (Machu et al. 2015). The supernatant was collected, and the remaining residues were subjected to re-extraction under the same condition. The resulting supernatants were combined, freeze dried and stored at $-20{ }^{\circ} \mathrm{C}$. The dried extracts were dissolved in distilled water prior to analysis.

To measure the total phenolic content, $200 \mu \mathrm{L}$ of the extraction sample was mixed with $200 \mu \mathrm{L}$ of Folin-Ciocalteu's phenol reagent and $1 \mathrm{~mL}$ of distilled water. After incubating the solution at room temperature and darkness for $5 \mathrm{~min}$, $200 \mu \mathrm{L}$ of $20 \%(\mathrm{w} / \mathrm{v}) \mathrm{Na}_{2} \mathrm{CO}_{3}$ was added and the solution volume was adjusted to $2 \mathrm{~mL}$ with distilled water. The mixture was incubated in darkness for $1 \mathrm{~h}$, and then the absorbency was measured at $765 \mathrm{~nm}$ (Machu et al. 2015). Gallic acid was used as standard. The total phenolic content was reported in $\mathrm{mg}$ gallic acid equivalent (GAE) per $\mathrm{g}$ dry extract.

\section{Reducing sugars}

The amount of reducing sugars was measured using a modified version of dinitrosalicylic acid assay (DNS assay) described previously (Stålbrand et al. 1993). In this modified assay, $60 \mu \mathrm{L}$ of the sample was mixed with $120 \mu \mathrm{L}$ of DNSreagent in a 96-well plate by pipetting up and down and stirring simultaneously. Standard samples were prepared by adding $6 \mu \mathrm{L}$ of glucose solution with different concentrations $(0-50 \mathrm{mM})$ to a mixture containing $54 \mu \mathrm{L}$ of either distilled water or $\mathrm{HCl} 0.1 \mathrm{M}$ and $120 \mu \mathrm{L}$ of DNS-reagent. The resulting samples were boiled in a PCR thermocycler (TProfessional Themocycle, Biometra, Germany) at $95{ }^{\circ} \mathrm{C}$ for $10 \mathrm{~min}$. After cooling, $150 \mu \mathrm{L}$ of the mixture was transferred into a flat-bottom 96-well plate and the absorbancy was measured at $540 \mathrm{~nm}$ using a Multiskan GO Microplate Spectrophotometer (Thermo Fisher Scientific). The experiment was carried out in triplicates. The amount of reducing sugars was reported in $\mathrm{mg} \mathrm{g}^{-1}$ dry weight.

\section{Elemental analysis}

An amount of $0.45 \mathrm{~g}$ of dried sample (seaweed ash or the extracts from the pre-treatments) was digested in a mixture containing $7 \mathrm{~mL}$ of concentrated $\mathrm{HNO}_{3}$ and $3 \mathrm{~mL}$ of distilled water in closed vessels in a microwave (Mars 5, CEM, USA). The volume of digested sample was adjusted to $50 \mathrm{~mL}$ by adding distilled water prior to analysis. The analysis was performed using Inductively Coupled Plasma Optical Emission Spectrometry (ICP-OES) (Optima 8300, Perkin Elmer, USA).

\section{Extraction yield and extracts dry weight}

For measuring the extraction yield, $1 \mathrm{~g}$ of the freeze-dried seaweed powder was subjected to the pre-treatments. The soluble fractions were collected after centrifuging at $3800 \times g$ for $10 \mathrm{~min}$ and freeze dried until a constant weight was achieved. The extraction yield (\%) was estimated as the weight of dried extract obtained from $1 \mathrm{~g}$ seaweed. The extract dry weight was calculated as dry weight of $1 \mathrm{~mL}$ soluble fractions collected from the pre-treatments. All measurements were carried out in triplicates.

\section{Carbohydrate composition quantification}

The total carbohydrate of the seaweed biomass was quantified after a two-step sulphuric acid hydrolysis treatment (Sluiter et al. 2008b). An amount of $2.50 \mathrm{~mL}$ of sulphuric acid $72 \%$ $(\mathrm{w} / \mathrm{w})$ was mixed with $0.25 \mathrm{~g}$ of the seaweed powder in a glass tube and incubated at $30{ }^{\circ} \mathrm{C}, 300 \mathrm{rpm}$ shaking for $60 \mathrm{~min}$. Then, the acid was diluted to $4 \%(\mathrm{w} / \mathrm{w})$ by adding distilled water, and the mixture was autoclaved at $121^{\circ} \mathrm{C}$ for $1 \mathrm{~h}$. The hydrolysate was cooled to room temperature and centrifuged at $3000 \times g$ for $5 \mathrm{~min}$. The supernatant was neutralized with $\mathrm{Ba}(\mathrm{OH})_{2} \cdot \mathrm{H}_{2} \mathrm{O}(0.1 \mathrm{M})$. In order to remove precipitated residues, the neutral supernatant was centrifuged at $3000 \times g$ for $5 \mathrm{~min}$. The hydrolysate was diluted and filtered through $0.2 \mu \mathrm{m}$ syringe filter and analysed using a HighPerformance Anion Exchange Chromatography system equipped with Pulsed Amperometric Detector (HPAECPAD) (Thermo Fisher Scientific, USA). Dionex CarboPac PA-20 analytical column and guard column (Thermo Fisher Scientific, Waltham, USA) were used to separate monosaccharides (Sluiter et al. 2008b). The separation of monosaccharides, neutral sugars and uronic acids was performed under isocratic condition at a flow rate of $0.5 \mathrm{~mL} / \mathrm{min}$. For neutral sugars, eluents were (A) milliQ-water, (B) $2 \mathrm{mM}$ sodium hydroxide and (C) $200 \mathrm{mM}$ sodium hydroxide. Separation of neutral sugars and mannitol was performed using an eluent mixture of $62.5 \%$ (A) and $37.5 \%$ (B) for $30 \mathrm{~min}$. For separating uronic acids eluent (B) was $1 \mathrm{M}$ sodium acetate in $200 \mathrm{mM}$ sodium hydroxide while eluent (A) and (C) were milliQ-water and $200 \mathrm{mM}$ sodium hydroxide, respectively. 
Uronic acids were eluted by an eluent mixture of $55 \%$ (A), $15 \%$ (B) and 30\% (C) for 18 min. The column and compartment temperature were kept at $30^{\circ} \mathrm{C}$. All the experiments were performed in duplicate, and the mean value and standard deviation were calculated. Total carbohydrates were estimated as the sum of all individual monomeric sugars. Oligosaccharide content of the extracts was analysed by HPAEC-PAD system using a Dionex CarboPac PA-200 analytical column (Thermo Fisher Scientific). The dried extracts were dissolved in milliQ-water and filtered through $0.2 \mu \mathrm{m}$ syringe filter. Eluents were (A) milliQ-water, (B) $400 \mathrm{mM}$ sodium acetate in $200 \mathrm{mM}$ sodium hydroxide and (C) $200 \mathrm{mM}$ sodium hydroxide. Oligosaccharides were separated by a linear gradient from zero to $45 \%$ (C) plus zero to $5 \%$ (B) in (A) at a flow rate of $0.5 \mathrm{~mL} \mathrm{~min}^{-1}$ for $20 \mathrm{~min}$.

\section{Molecular weight of polysaccharides}

The molecular weights of the polysaccharides in the extracts were estimated by size exclusion chromatography using a HPLC system (Agilent Technologies, USA) equipped with Refractive-Index detector (ERC-7510, ERMA INC). An HPLC column $(16 \mathrm{~mm} \times 600 \mathrm{~mm})$ was packed with Sephacryl S-200 HR resin with a molecular weight separation range of $1-80 \mathrm{kDa}$ (GE Healthcare Life Sciences) and used to estimate the molecular weights of the polysaccharides in the extracts from hot water and acid pre-treatment. MilliQ-water was used as eluent at a flow rate of $0.3 \mathrm{~mL} \mathrm{~min}^{-1}$ for $400 \mathrm{~min}$. Dextran standards (5-80 kDa) were used to plot the standard curve.

\section{Results}

\section{Characterization of Laminaria digitata biomass}

The chemical composition of the two L. digitata batches was compared with analogous data from previous studies by Adams et al. (2011) and Schiener et al. (2015) using $L$. digitata with the same harvesting season (Table 1). Ash was analysed via similar analytical methods in all studies. The protein content of the two batches was analysed by both the Kjeldahl and Dumas methods, and the results were comparable using the respective method (Data not shown). Ash, protein and total phenolic content in our study were higher in batch LAM 50 compared with batch LAM 50/20 and the studies by Adams et al. (2011) and Schiener et al. (2015). Both batches had significantly higher proportion of total phenolic content compared to data obtained by Schiener and coworkers (2015). The analytical assay for measuring total phenolic content was similar in all studies; however, in this study, the conditions used for the extraction of phenolic compounds were optimized (see "Materials and methods"), which could be a reason for the higher content.
It was observed that batch LAM 50 contained lower proportion of mannitol and higher proportion of uronic acids compared with LAM 50/20. The glucose content was, however, slightly higher in LAM 50, compared with LAM 50/20, indicating higher amount of storage glucan. The amount of other sugars was similar in both batches. The majority of the carbohydrate content of LAM 50 corresponded to uronic acids ( $24 \%$ out of $47 \%$ ), which is in agreement with the data obtained by Schiener et al. (2015), showing that the alginate is the major polysaccharide in the seaweed biomass. Indeed, in batch LAM 50 the concentration of uronic acids was twice as high as mannitol and far above the glucose. In LAM 50/20, the amount of uronic acids and mannitol was almost similar and again much higher than the amount of glucose. Other sugars (i.e. fucose, galactose and xylose, judged to originate from fucoidan) made up less than $5 \%$ of the seaweed carbohydrates. The results for total carbohydrates in our study were in agreement with the results from previous studies (Schiener et al. 2015); however, the ratio of analysed components showed some differences. The ratio of mannuronic acid to guluronic acid (M/G ratio) was calculated to 0.87 and 0.9 for LAM 50 and LAM 50/20 batches, respectively. Although the $\mathrm{M} / \mathrm{G}$ ratio was almost equal for both batches, it was lower than previously estimated ratios from $L$. digitata: 1.12 determined by Fertah et al. (2017) and 1.5 reported by Papageorgiou et al. (2008). This may however be dependent on if standards were subjected to the same treatment as samples (which was the case here) as the guluronic acid is more sensitive to degradation, leading to a risk of underestimation.

The fine powder seaweed, batch (LAM 50), was here chosen for the further pre-treatment experiments because of the smaller particle size and higher total amount of carbohydrates (Table 1).

Minerals, heavy metals and trace elements of the seaweed batch LAM 50 are shown in Table 2. The concentrations of major elements were in the following order: $\mathrm{K}>\mathrm{Na}>\mathrm{Ca}>$ $\mathrm{Mg}$, which was in agreement with the data described by Schiener et al. (2015) and Adams et al. (2011). Also, other elements including $\mathrm{P}, \mathrm{Fe}, \mathrm{Mn}, \mathrm{Zn}, \mathrm{As}, \mathrm{Cu}$ and $\mathrm{Cd}$ were observed in the seaweed.

Precise comparisons of mineral and heavy metal content of the seaweed with other studies is difficult due to the seasonal, environmental, geographical and physiological variations (Mabeau and Fleurence 1993). However, considering Ca, $\mathrm{Cu}, \mathrm{Fe}, \mathrm{K}, \mathrm{Mg}, \mathrm{Mn}, \mathrm{Na}$ and $\mathrm{Zn}$, Rupérez (2002) reported a mineral content of around $170 \mathrm{mg} \mathrm{g}^{-1} \mathrm{DW}$ for L. digitata, harvested in Spain and Schiener and co-workers(2015) reported approximately $120 \mathrm{mg} \mathrm{g}^{-1} \mathrm{DW}$ for $L$. digitata harvested in February 2011 in Clachan Sound, Scotland. Notably, in our study, the mineral content including mentioned minerals and trace elements was calculated $173 \mathrm{mg} \mathrm{g}^{-1} \mathrm{DW}$, in line with the content reported by Rupérez (2002). 
Table 1 Composition analysis of two batches of L. digitata (LAM 50 and LAM 50/20) and comparison with other studies

\begin{tabular}{|c|c|c|c|c|}
\hline $\begin{array}{l}\text { Composition } \\
{\left[\% \mathrm{DW}^{\mathrm{a}}\right]}\end{array}$ & LAM 50 & LAM $50 / 20$ & $\begin{array}{l}\text { L. digitata from Aberystwyth } \\
\text { beach, } \mathrm{UK}^{\mathrm{b}} \text {, harvested Jan-Mar } \\
2008 \text { (Adams et al. 2011) }\end{array}$ & $\begin{array}{l}\text { L. digitata from Clachan Sound }{ }^{\mathrm{c}} \text {, } \\
\text { UK, harvested Aug } 2010-\text { Oct } 2011 \\
\text { (Schiener et al. 2015) }\end{array}$ \\
\hline Ash & $41.8 \pm 0.4$ & $31.9 \pm 0.2$ & $27-33$ & $31.6 \pm 7.1$ \\
\hline Protein & $8.45^{\mathrm{e}}$ & 7.00 & $\mathrm{ND}^{\mathrm{d}}$ & $\begin{array}{l}6.9 \pm 1.1 \\
\text { (Lowry assay) }\end{array}$ \\
\hline Total phenolic content & $4.4 \pm 0.1$ & $3.0 \pm 0.1$ & ND & 0.15 \\
\hline Mannitol & $10.55 \pm 0.33$ & $16.49 \pm 0.27$ & 5 & $6-8$ \\
\hline Fucose & $2.55 \pm 0.04$ & $2.49 \pm 0.04$ & ND & ND \\
\hline Galactose & $0.79 \pm 0.02$ & $0.52 \pm 0.04$ & ND & ND \\
\hline Glucose & $8.43 \pm 0.01$ & $6.47 \pm 1.07$ & Very low & $1-3$ (laminarin) and $11 \%$ cellulose \\
\hline Xylose & $0.40 \pm 0.01$ & $0.44 \pm 0.01$ & ND & ND \\
\hline Mannuronic acid & $11.24 \pm 0.30$ & $8.20 \pm 0.84$ & ND & ND \\
\hline Guluronic acid & $12.82 \pm 1.92$ & $9.03 \pm 0.15$ & ND & ND \\
\hline Glucuronic acid & $0.41 \pm 0.04$ & $0.25 \pm 0.01$ & ND & ND \\
\hline Total uronic acids & $24.47 \pm 2.26$ & $17.47 \pm 1.00$ & ND & $\sim 22-27$ \\
\hline Total carbohydrates & $46.68 \pm 1.66$ & $43.88 \pm 2.43$ & ND & $\sim 44$ \\
\hline
\end{tabular}

Data represents mean value \pm standard deviation (for ash and total phenolic content, $n=3$; for monosaccharides, $n=2$ )

${ }^{\text {a }}$ DW means dry weight

${ }^{\mathrm{b}}$ Aberystwyth beach, Ceredigion, UK (ordnance survey reference SN 581823)

${ }^{\mathrm{c}}$ Sheltered shores of the Clachan Sound on the Isle of Seil, Scotland (OS grid coordinates NM 78517 19,700)

${ }^{\mathrm{d}} \mathrm{ND}$ means not determined

${ }^{\text {e }}$ Single sample was analysed by the Dumas method

\section{Pre-treatment of $L$. digitata biomass}

\section{Effect of mild acid and hot water pre-treatment on L. digitata biomass}

The effect of hot water and mild acid pre-treatments was investigated by analysing the collected soluble and insoluble fractions.

The extraction yield (g extract/g dry biomass) from $1 \mathrm{~g}$ seaweed subjected to acid pre-treatment was calculated to $22.4 \pm$ $0.8 \%$ and for 20-min and 60-min hot water pre-treatments was slightly higher, estimated to $27.0 \pm 5.2 \%$ and $27.4 \pm 3.3 \%$, respectively. The extract dry weight obtained from acid pretreatment was calculated to $53.5 \pm 1.8 \mathrm{~g} \mathrm{~L}^{-1}$, and from 20-min and 60-min hot water pre-treatment, it was estimated to $57.2 \pm$ 2.1 and $59.5 \pm 0.75 \mathrm{~g} \mathrm{~L}^{-1}$, respectively.

Composition analyses of the soluble and insoluble fractions after the respective pre-treatment are illustrated in Table 3 . Overall, the extracts from hot water pre-treatments contained less ash and more proteins, total phenolic compounds and carbohydrates compared with the extract from acid pre-treatment. The reverse trend can be seen in the composition of remaining solid residues except for phenolic compounds, which was lower in the solid residues from acid pre-treatment.

The monosaccharide composition, obtained after hydrolysis of the polysaccharides, in the extracts from hot water and acid pre-treatments are shown in Table 3. The amount of neutral sugars was slightly higher in the extract from 20min hot water pre-treatment than in the extract where the treatment was extended to $60 \mathrm{~min}$ or where the seaweeds were subjected to acid pre-treatment. An opposite trend was seen for the uronic acids content in the extract from 20-min hot water pre-treatment, which was slightly lower than after 60-min hot water pre-treatment. The amount of uronic acids in the extract from acid pre-treatment was very low compared with those solubilized after hot water pre-treatments (Fig. 2). The carbohydrates were however not detectable as monosaccharides or oligosaccharides in the soluble fraction as analysis of the extracts by HPAEC-PAD (before subjecting to acid hydrolysis) showed that only negligible amounts of monosaccharides (e.g. glucose below $0.2 \%$ ) and short oligosaccharides were present in the respective extract (Data not shown).

Table 2 Micronutrients in L. digitata seaweed $\left(\mathrm{mg} \mathrm{g}^{-1} \mathrm{DW}\right)$ determined by atomic absorption spectrophotometry (batch LAM 50)

\begin{tabular}{lllllllllllllll}
\hline As & $\mathrm{Ca}$ & $\mathrm{Cd}$ & $\mathrm{Cu}$ & $\mathrm{Fe}$ & $\mathrm{K}$ & $\mathrm{Mg}$ & $\mathrm{Mn}$ & $\mathrm{Na}$ & $\mathrm{P}$ & $\mathrm{Zn}$ & $\mathrm{Hg}$ & $\mathrm{Se}$ \\
\hline 0.009 & 37.74 & 0.0002 & 0.005 & 2.523 & 85.485 & 9.552 & 0.036 & 37.829 & 3.93 & 0.009 & $\mathrm{BDL}^{\mathrm{a}}$ & $\mathrm{BDL}^{\mathrm{a}}$ \\
\hline
\end{tabular}

${ }^{\mathrm{a}} \mathrm{BDL}$ means below detection limit 
Table 3 Composition analysis of the soluble and insoluble fractions from mild acid and hot water pre-treatment of L. digitata (batch LAM 50). All polysaccharides were hydrolysed prior to analysis, and carbohydrate content measured from the resulting monosaccharides

\begin{tabular}{|c|c|c|c|c|c|c|}
\hline \multirow{3}{*}{$\begin{array}{l}\text { Composition } \\
{[\% \text { DW] }}\end{array}$} & \multicolumn{6}{|c|}{ Pre-treatment methods } \\
\hline & \multicolumn{2}{|c|}{ Mild acid ( $\mathrm{HCl} 0.1 \mathrm{M})$} & \multicolumn{2}{|c|}{ Hot water (20 min) } & \multicolumn{2}{|c|}{ Hot water (60 min) } \\
\hline & Soluble fraction & Insoluble fraction & Soluble fraction & Insoluble fraction & $\begin{array}{l}\text { Soluble } \\
\text { fraction }\end{array}$ & Insoluble fraction \\
\hline Ash & $54.1 \pm 0.2$ & $30.0 \pm 0.5$ & $49.0 \pm 1.9$ & $37.4 \pm 3.0$ & $45.7 \pm 2.8$ & $37.1 \pm 1.2$ \\
\hline Protein & 5.26 & 11.8 & 6.88 & 10.53 & 6.98 & 9.39 \\
\hline Reducing sugars & $11.63 \pm 0.60$ & - & $12.35 \pm 0.1$ & - & $17.63 \pm 0.714$ & - \\
\hline Total phenolic content & $2.83 \pm 0.15$ & $4.07 \pm 0.09$ & $2.84 \pm 0.18$ & $6.29 \pm 0.97$ & $3.20 \pm 0.03$ & $6.45 \pm 0.19$ \\
\hline Mannitol & $15.41 \pm 0.11$ & $5.62 \pm 0.03$ & $17.50 \pm 0.55$ & $7.14 \pm 0.42$ & $16.1 \pm 0.98$ & $6.74 \pm 0.144$ \\
\hline Fucose & $3.43 \pm 0.15$ & $2.17 \pm 0.00$ & $4.63 \pm 0.101$ & $1.62 \pm 0.06$ & $4.55 \pm 0.05$ & $1.48 \pm 0.09$ \\
\hline Galactose & $0.58 \pm 0.00$ & $0.68 \pm 0.10$ & $1.042 \pm 0.02$ & $0.55 \pm 0.00$ & $0.88 \pm 0.01$ & $0.46 \pm 0.02$ \\
\hline Glucose & $5.15 \pm 0.11$ & $5.11 \pm 0.26$ & $5.42 \pm 0.03$ & $7.92 \pm 1.66$ & $5.03 \pm 0.07$ & $4.77 \pm 0.1$ \\
\hline Xylose & $\mathrm{BDL}^{\mathrm{a}}$ & $0.46 \pm 0.00$ & $0.57 \pm 0.00$ & $0.31 \pm 0.01$ & $0.47 \pm 0.01$ & $0.22 \pm 0.03$ \\
\hline Mannuronic acid & $0.43 \pm 0.01$ & $9.09 \pm 0.11$ & $3.27 \pm 0.50$ & $7.99 \pm 2.60$ & $3.53 \pm 0.9$ & $6.13 \pm 0.19$ \\
\hline Guluronic acid & $0.79 \pm 0.02$ & $10.46 \pm 0.06$ & $2.40 \pm 0.32$ & $7.21 \pm 2.45$ & $2.98 \pm 0.35$ & $7.01 \pm 0.15$ \\
\hline Glucuronic acid & BDL & $\mathrm{BDL}$ & BDL & BDL & $\mathrm{BDL}$ & BDL \\
\hline Total carbohydrate & $25.79 \pm 0.4$ & $33.58 \pm 0.55$ & $34.83 \pm 1.52$ & $32.72 \pm 7.76$ & $33.53 \pm 2.38$ & $26.81 \pm 0.71$ \\
\hline
\end{tabular}

Data represents mean value \pm standard deviation (for ash and total phenolic content, $n=3$; for monosaccharides, $n=2$ )

${ }^{\mathrm{a}} \mathrm{BDL}$ means below detection limit

Considering the concentration of carbohydrates in both soluble and insoluble fractions, more than $90 \%$ of fucoidan was recovered in all pre-treatment methods. Alginate was mostly recovered during acid pre-treatment (63\% sugar recovery), and for laminarin, maximum sugar recovery of $86 \%$ was obtained over 20-min hot water pre-treatment(Fig. 2a).

Elemental analysis of the soluble fractions from acid and hot water pre-treatments is shown in Table 4. Notably, the amount of calcium was significantly higher in the extract from acid pre-treatment, due to the release of $\mathrm{Ca}$ when $\mathrm{Ca}$-alginate is transferred to alginic acid. In addition, the concentration of $\mathrm{K}, \mathrm{Mg}$, Na and $\mathrm{P}$ was slightly higher in the extract from acid pre-treatment than that in the extracts from hot water pre-treatments. Some heavy metals including $\mathrm{As}$ and $\mathrm{Cd}$ and some salts such as $\mathrm{Na}$ were enriched in the extracts (Table 4) compared with the original material (Table 2).
The concentration of As, $\mathrm{Cd}$ and $\mathrm{Hg}$ in all extracts was higher than the recommended values for food products (Mabeau and Fleurence 1993; Besada et al. 2009); hence, if materials are intended for use in food and feed applications, there is a need of selective removal.

\section{Fractionation and analysis of polysaccharide content of the extracts}

The three different extracts were analysed by size exclusion chromatography. The results showed that the extracts contained several overlapping peaks with a wide range of molecular weights. Fractions with a range of molecular weights, corresponding to broad peaks were collected, freeze dried, hydrolysed to monosaccharides and analysed (Table 5).
Fig. 2 Total recovery (a) and extraction yield (b) of fucoidan, laminarin and alginate in acid pretreatment and 20-min and 60-min hot water pre-treatments a

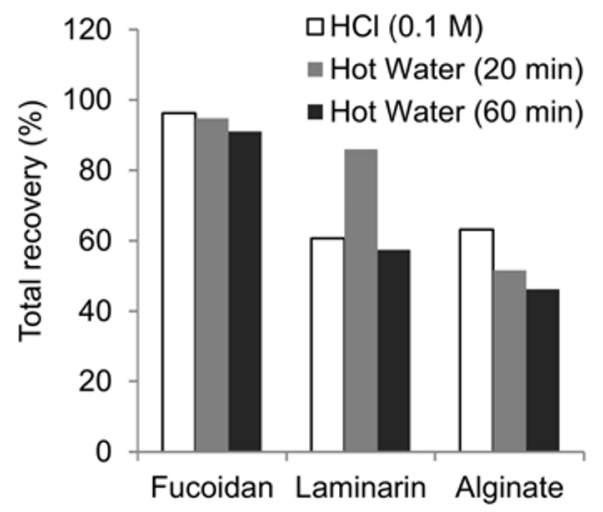

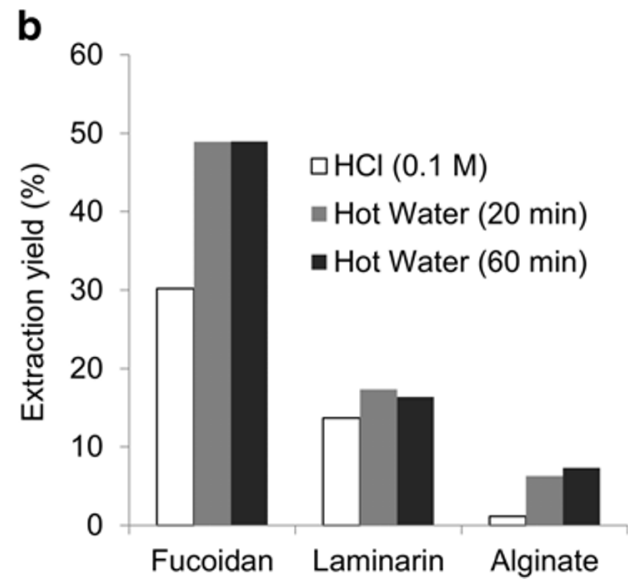


Table 4 Minerals, heavy metals and elements determined by atomic absorption spectrophotometry in the soluble fraction after the pretreatment of $L$. digitata

\begin{tabular}{llll}
\hline \multicolumn{3}{l}{ Composition $\left[\mathrm{mg} \mathrm{g}^{-1}\right.$ dry material $]$} \\
\cline { 2 - 3 } & \multicolumn{2}{l}{ Pre-treatment methods } \\
\cline { 2 - 3 } & $0.1 \mathrm{M} \mathrm{HCl}$ & Hot water $(60 \mathrm{~min})$ & Hot water $(20 \mathrm{~min})$ \\
\hline $\mathrm{As}$ & 0.089 & 0.079 & 0.077 \\
$\mathrm{Ca}$ & 26.6 & 6.3 & 4.50 \\
$\mathrm{Cd}$ & 0.002 & 0.001 & 0.002 \\
$\mathrm{Cu}$ & 0.001 & 0.0004 & 0.0003 \\
$\mathrm{Fe}$ & 0.055 & 0.030 & 0.033 \\
$\mathrm{Hg}$ & 0.003 & 0.004 & 0.002 \\
$\mathrm{~K}$ & 141.8 & 128.9 & 131.1 \\
$\mathrm{Mg}$ & 13.0 & 9.40 & 8.30 \\
$\mathrm{Mn}$ & 0.02 & 0.002 & 0.005 \\
$\mathrm{Na}$ & 60.9 & 53.8 & 48.50 \\
$\mathrm{P}$ & 4.0 & 2.7 & 2.70 \\
$\mathrm{Se}$ & 0.0016 & 0.0005 & 0.001 \\
$\mathrm{Zn}$ & $\mathrm{BDL}$ & $\mathrm{BDL}$ & $\mathrm{BDL}$ \\
\hline
\end{tabular}

${ }^{\mathrm{a}} \mathrm{BDL}$ means below detection limit

In the extract from acid pre-treatment, peaks with a total molecular weight range 5 to $55 \mathrm{kDa}$ were collected, and all fractions were composed of all neutral sugars and trace amount of uronic acid. This indicates interaction between the polysaccharides in the extract. The carbohydrate content of the fractions collected in the lower molecular weight range was lower than the content in fractions at the higher molecular weight ranges. Since the molecular weight of mannitol is only $182 \mathrm{Da}$, the presence of mannitol in the fractions with molecular weight of above $5 \mathrm{kDa}$ is probably due to interactions between mannitol, laminarin and alginate, as well as mannitol included in laminarin termini (Read et al. 1996; Chizhov et al. 1998; Dianawati et al. 2012).

Both hot-water extracts (from 20-min and 60-min hot water pre-treatments) had rather similar size exclusion chromatography profiles. At molecular weights above $17-20 \mathrm{kDa}$, the fractions from both extracts (20-min and 60-min hot water pre-treatments, respectively) were predominantly made up from fucose and uronic acids, which is likely due to existence of alginate and fucoidan polymers or macromolecular complexes formed because of the ionic interactions. In the fractions with molecular weights from 5 to $17 \mathrm{kDa}$, the amount of fucose and uronic acids decreased while the concentration of glucose and mannitol increased in the extract, indicating presence of laminarin. The fraction with molecular weight below $5 \mathrm{kDa}$ contained significant amount of mannitol (as expected from its low molecular weight), and this was observed in all extracts, including the extract from acid pre-treatment.

\section{Alginate extraction from the solids after acid pre-treatment}

The extraction yield and purity of the alginate are affected by the $\mathrm{pH}$ of the alkaline solution, the extraction time and the

Table 5 Carbohydrate analysis of the peak fractions isolated by size exclusion chromatography of the extracts from pre-treatment of $L$. digitata. The indicated molecular weight range is estimated based on dextran standards

\begin{tabular}{|c|c|c|c|c|c|c|c|c|c|c|}
\hline \multicolumn{11}{|c|}{ Composition [\% dry material] } \\
\hline $\begin{array}{l}\mathrm{MW} \\
(\mathrm{kDa})\end{array}$ & Mannitol & Fucose & Galactose & Glucose & Xylose & $\begin{array}{l}\text { Mannuronic } \\
\text { acids }\end{array}$ & $\begin{array}{l}\text { Guluronic } \\
\text { acids }\end{array}$ & $\begin{array}{l}\text { Glucuronic } \\
\text { acids }\end{array}$ & $\begin{array}{l}\text { Total neutral } \\
\text { sugars }\end{array}$ & $\begin{array}{l}\text { Uronic } \\
\text { acids }\end{array}$ \\
\hline \multicolumn{11}{|c|}{ Extract from mild acid pre-treatment } \\
\hline $37-55$ & 13.18 & 15.71 & 2.75 & 20 & 1.04 & 2.17 & 2.93 & 0.12 & 52.68 & 5.22 \\
\hline $11-37$ & 14.78 & 10.91 & 1.9 & 18.38 & 0.7 & 2.13 & 2.45 & 0.1 & 46.67 & 4.68 \\
\hline $5-11$ & 18.25 & 6.6 & 1.15 & 14.67 & 0.3 & 1.59 & 1.67 & 0.01 & 40.97 & 3.27 \\
\hline$<5$ & 15.86 & 0.69 & 0.11 & 3.33 & 0 & 0.86 & 0.39 & 0 & 19.99 & 1.25 \\
\hline \multicolumn{11}{|c|}{ Extract from 60 -min hot water pre-treatment } \\
\hline $37-67$ & 0 & 13.53 & 4.34 & 0.47 & 2.76 & 14.11 & 9.01 & 0.62 & 21.1 & 23.74 \\
\hline $20-37$ & 0 & 16.3 & 3.96 & 6.72 & 2.83 & 23.08 & 12.56 & 0.88 & 29.81 & 36.52 \\
\hline $14-20$ & 1.98 & 13.11 & 2.4 & 10.81 & 1.54 & 22.34 & 10.13 & 0.61 & 29.84 & 33.08 \\
\hline $5-14$ & 6.85 & 8.53 & 1.25 & 12.05 & 0.87 & 10.68 & 4.8 & 0.42 & 29.55 & 15.90 \\
\hline$<5$ & 14.35 & 2.41 & 0.343 & 4.16 & 0.183 & 4.46 & 1.94 & 0 & 21.446 & 6.40 \\
\hline \multicolumn{11}{|c|}{ Extract from 20-min hot water pre-treatment } \\
\hline $37-67$ & 0 & 13.9 & 5.2 & 0.67 & 3.02 & 16.04 & 11.61 & 1.05 & 22.79 & 28.70 \\
\hline $17-37$ & 0 & 13.77 & 3.75 & 6.03 & 2.48 & 19.73 & 10.92 & 0.68 & 26.03 & 31.33 \\
\hline $5-17$ & 10.32 & 9.6 & 1.69 & 12.16 & 1.2 & 15.34 & 7.27 & 0.3 & 34.97 & 22.91 \\
\hline$<5$ & 17.6 & 2.61 & 0.39 & 4.36 & 0.26 & 4.7 & 2 & 0.03 & 25.22 & 6.73 \\
\hline
\end{tabular}


temperature. Generally, extraction of alginate is performed at $\mathrm{pH} 10$, at a temperature from 50 to $95^{\circ} \mathrm{C}$ with a reaction time of 1-2 h(McHugh 1987; Vauchel et al. 2008a).

The alginate in the remaining solid residues from acid pretreatment of $L$. digitata was extracted using such conventional methods (Table 6). Two solutions $\left(\mathrm{Na}_{2} \mathrm{CO}_{3}(0.15 \mathrm{M})\right.$ and $\mathrm{NaOH}(0.3 \mathrm{M})$ ) were used for the extraction of alginate and two solutions (ethanol $(95 \%)$ and $\mathrm{CaCl}_{2}(10 \%)$ ) were used for the precipitation of alginate salt. The results showed that complete extraction and maximum recovery were achieved when $\mathrm{Na}_{2} \mathrm{CO}_{3}$ was used for the extraction and $\mathrm{CaCl}_{2}(10 \%)$ was used for the precipitation (Table 6). The carbohydrate analysis of the remaining solid residues after alginate extraction with $\mathrm{Na}_{2} \mathrm{CO}_{3}$ showed that almost all alginates were extracted (Table 6). However, the maximum alginic acid recovery of $62.2 \%$ showed that some degradation must have occurred during the extraction process, which may have affected the $\mathrm{M} / \mathrm{G}$ ratio (see below). The proportion of other sugars in the extracted alginic acid fraction was below $1 \%$ (analysed by HPAEC-PAD after acid hydrolysis), meaning that the collected alginic acid was pure. Finally, the $\mathrm{M} / \mathrm{G}$ ratio of the extracted alginate was calculated to be 1.29 , which was higher than that for the raw seaweed material (M/G: 0.87), indicating that degradation of guluronic acid-rich regions must have occurred.

\section{Shake flask cultivation of Rhodothermus marinus DSM 16675 using different marine polysaccharides as sole carbon sources}

The growth data of $R$. marinus in the presence of glucose and laminarin at final concentrations of $5 \mathrm{~g} \mathrm{~L}^{-1}$ and in the presence of commercial sodium alginate (high and low viscosity) at a concentration of $10 \mathrm{~g} \mathrm{~L}^{-1}$ showed that this bacterium was able to utilize all three carbon sources (Table 7). The medium containing alginate as the carbon source, especially the high viscosity kind, was very viscous and cloudy, which resulted in apparent higher optical density (OD) measurements at the beginning of the cultivation. However, after $24 \mathrm{~h}$, the cultures were watery and highly red in colour, indicating degradation and utilization of the alginate polymer. Interlaboratory comparison of the growth on alginate revealed strain differences
Table 7 Growth data of $R$. marinus in the medium containing glucose $\left(5 \mathrm{~g} \mathrm{~L}^{-1}\right)$, laminarin $\left(5 \mathrm{~g} \mathrm{~L}^{-1}\right)$, alginate $\left(10 \mathrm{~g} \mathrm{~L}^{-1}\right)$ and medium without any carbon source

\begin{tabular}{lllll}
\hline & $\begin{array}{l}\mathrm{OD}_{620} \\
\text { No carbon source }\end{array}$ & Glucose & Laminarin & $\begin{array}{l}\text { Alginate } \\
\mathrm{Hv} / \mathrm{Lv}^{\mathrm{a}}\end{array}$ \\
\hline$t=0$ & $0.18 \pm 0.001$ & $0.17 \pm 0.06$ & $0.17 \pm 0.01$ & $0.82 / 0.3$ \\
$t=24 \mathrm{~h}$ & $0.43 \pm 0.06$ & $5.66 \pm 1.29$ & $3.94 \pm 1.30$ & $4.66 / 2.44$ \\
\hline
\end{tabular}

Standard deviation of measured values from duplicate cultures is indicated

${ }^{a} \mathrm{Hv}$ means high viscosity; Lv means low viscosity

and a need of adaptation of $R$. marinus for successful utilization of this carbon source. Direct use of the strain from the type culture collection resulted in low or negligible growth, and trials involving two laboratories resulted in a large variation in the final cell densities obtained. The data reported in Table 7 were obtained after repeated inoculations. As the genome of $R$. marinus has a complete set of genes encoding various alginate degrading enzymes, the bottleneck may be a need to either induce the enzymes or trigger uptake of relevant degradation products.

In the presence of the extract from acid pre-treatment, the OD after a period of $24 \mathrm{~h}$ cultivation was significantly increased (3.28 \pm 0.28$)$, showing that cell growth occurred using $2 \%(\mathrm{w} / \mathrm{v})$ extract in a medium with a starting concentration of $3 \mathrm{~g} \mathrm{~L}^{-1}$ mannitol, $1 \mathrm{~g} \mathrm{~L}^{-1}$ glucose and $0.7 \mathrm{~g} \mathrm{~L}^{-1}$ fucose (Table 8 ). The maximum OD was lower in medium supplemented with $4 \%$ extract $(1.75 \pm 0.09)$, probably due to the existence of compounds with growth inhibitory effects.

In the presence of the extracts from hot water pre-treatment, maximum growth was obtained in the medium containing $1 \%$ (w/v) extract (1.45 \pm 0.1$)$, but with a maximum OD far below the maximum observed in the presence of the extract from acid pre-treatment $(2 \% \mathrm{w} / \mathrm{v})$ or when pure glucose was used as carbon source.

As shown earlier (Table 3), the concentration of fucoidan in the extract from hot water treatment was higher than that in the extract from acid pre-treatment. Antimicrobial effects, previously reported for several types of sulphated fucoidans (Jönsson et al. 2020), could be a reason for the less significant
Table 6 Composition analysis of the extracted alginate and remaining solid residues after alginate extraction

\begin{tabular}{|c|c|c|c|c|c|}
\hline \multirow{2}{*}{$\begin{array}{l}\text { Extraction } \\
\text { solution }\end{array}$} & \multirow{2}{*}{$\begin{array}{l}\text { Precipitation } \\
\text { solution }\end{array}$} & \multicolumn{2}{|c|}{ Uronic acids (\% dry extract) } & \multirow{2}{*}{$\begin{array}{l}\text { Alginic acid } \\
\text { recovery }(\%)\end{array}$} & \multirow{2}{*}{$\begin{array}{l}\mathrm{M} / \mathrm{G} \\
\text { ratio }\end{array}$} \\
\hline & & $\begin{array}{l}\text { Extracted } \\
\text { alginate }\end{array}$ & $\begin{array}{l}\text { Remaining solid residues } \\
\text { after extraction }\end{array}$ & & \\
\hline \multirow[t]{2}{*}{$\mathrm{Na}_{2} \mathrm{CO}_{3}$} & Ethanol & 30.06 & $\mathrm{BDL}^{\mathrm{a}}$ & 37.78 & 1.29 \\
\hline & $\mathrm{CaCl}_{2}$ & 25.64 & BDL & 62.21 & 1.29 \\
\hline \multirow[t]{2}{*}{$\mathrm{NaOH}$} & Ethanol & 22.83 & 23.39 & 4.18 & 1.61 \\
\hline & $\mathrm{CaCl}_{2}$ & 6.35 & 24.06 & 1.62 & 2.18 \\
\hline
\end{tabular}

${ }^{\mathrm{a}} \mathrm{BDL}$ means below detection limit 
Table 8 Growth data presented as cell density (optical density at $600 \mathrm{~nm}$ ) of $R$. marinus in a growth medium containing extracts from acid and hot water pre-treatment as carbon source

\begin{tabular}{|c|c|c|c|c|c|c|}
\hline & $\begin{array}{l}\text { No carbon } \\
\text { source }\end{array}$ & $0.50 \%$ & $1 \%$ & $2 \%$ & $4 \%$ & $\begin{array}{l}\text { Glucose } \\
\left(5 \mathrm{~g} \mathrm{~L}^{-1}\right)\end{array}$ \\
\hline \multicolumn{7}{|c|}{ Extract from mild acid pre-treatment } \\
\hline$t=0 \mathrm{~h}$ & $0.21 \pm 0.01$ & $0.26 \pm 0.1$ & $0.25 \pm 0.04$ & $0.21 \pm 0.03$ & $0.24 \pm 0.1$ & $0.17 \pm 0.06$ \\
\hline$t=24 \mathrm{~h}$ & $0.34 \pm 0.04$ & $0.72 \pm 0.11$ & $1.61 \pm 0.21$ & $3.28 \pm 0.28$ & $1.75 \pm 0.07$ & $5.66 \pm 1.29$ \\
\hline \multicolumn{7}{|c|}{ Extract from 20-min hot water pre-treatment } \\
\hline$t=0 \mathrm{~h}$ & $0.14 \pm 0.00$ & $0.14 \pm 0.00$ & $0.15 \pm 0.00$ & $0.14 \pm 0.02$ & $0.14 \pm 0.01$ & $0.17 \pm 0.06$ \\
\hline$t=24 \mathrm{~h}$ & $0.34 \pm 0.04$ & $0.66 \pm 0.04$ & $1.14 \pm 0.16$ & $0.48 \pm 0.16$ & $0.09 \pm 0.08$ & $5.66 \pm 1.29$ \\
\hline \multicolumn{7}{|c|}{ Extract from 60 -min hot water pre-treatment } \\
\hline$t=0 \mathrm{~h}$ & $0.14 \pm 0.00$ & $0.14 \pm 0.001$ & $0.14 \pm 0.00$ & $0.11 \pm 0.01$ & $0.13 \pm 0.0$ & $0.17 \pm 0.06$ \\
\hline$t=24 \mathrm{~h}$ & $0.34 \pm 0.04$ & $0.59 \pm 0.085$ & $1.45 \pm 0.1$ & $0.39 \pm 0.30$ & $0.315 \pm 0.05$ & $5.66 \pm 1.29$ \\
\hline
\end{tabular}

Standard deviation of measured values from duplicate cultures is indicated growth in the presence of the extracts from hot water pretreatments.

Mannitol was not utilized by $R$. marinus. In the genome sequence of $R$. marinus, genes involving mannitol uptake were not found. Lack of growth was confirmed by inoculating the bacterium in a medium containing mannitol as a sole carbon source. No increase in OD was observed in these cell cultures (data not shown).

\section{B. methanolicuswild-type strain MGA3 cultivation in the presence of mannitol and the extracts from Laminaria digitata pre-treatment}

Cultivations of the model strain B. methanolicus MGA3 was performed with the extracts of $L$. digitata prepared by mild acid $(\mathrm{HCl} 0.1 \mathrm{M})$ and hot water pre-treatment (20 or $60 \mathrm{~min})$. Initial cultivations were performed in deep well-plates by using minimal medium containing different concentrations of the extract $(25,50$ or $75 \% \mathrm{v} / \mathrm{v}$ corresponding to approximately $1.4,2.8$ and $4.2 \mathrm{~g} \mathrm{~L}^{-1}$, respectively). Minimal medium with mannitol (10 $\left.\mathrm{g} \mathrm{L}^{-1}\right)$ as sole carbon source, $\mathrm{Man}_{10}$-medium (Brautaset et al. 2004; Jakobsen et al. 2006) was used as a positive control, and the final $\mathrm{OD}_{600}$ was recorded for all growth conditions. Both 25 and $50 \%$ (v/v) extract supported growth of the strain MGA3 under these conditions, whereof extract prepared by 20-min hot water pre-treatment supported the highest biomass formation (Fig. 3) when using 50\% (v/v) extract in the medium. Little or no growth was detected for cultures in the presence of $75 \%$ extract, for the three different extracts tested (results not shown). Based on these initial experiments, extract from 20-min hot water pre-treatment of $L$. digitata was selected for further testing in shake flask cultivations of $B$. methanolicus strain MGA3.

Experiments in shake flasks were performed with 25 and $50 \%(\mathrm{v} / \mathrm{v})$ seaweed extract added to minimal medium ( $\mathrm{SWE}_{25^{-}}$and $\mathrm{SWE}_{50}$-medium), corresponding to a mannitol concentration of 2.5 and $5 \mathrm{~g} \mathrm{~L}^{-1}$, respectively. To ensure sufficient amount of available carbon source, parallel cultivations were performed in which additional mannitol was added to the cultures to yield the same final estimated mannitol concentration $\left(8.1 \mathrm{~g} \mathrm{~L}^{-1}\right)$ for all cultures.

A final $\mathrm{OD}_{600}$ of $2.0 \pm 0.2$ was reached for strain MGA3 cultivated in both $\mathrm{SWE}_{25}$ and $\mathrm{SWE}_{50}$ medium, corresponding to approximately 85 and $55 \%$ of the maximum $\mathrm{OD}_{600}$ values obtained during the growth on $\mathrm{Man}_{2.5^{-}}$and $\mathrm{Man}_{4.5^{-} \text {-medium }}$ (containing 2.5 and $4.5 \mathrm{~g} \mathrm{~L}^{-1}$ mannitol) respectively, as shown in Table 9.

Approximately $5 \mathrm{~g} \mathrm{~L}^{-1}$ of mannitol are consumed in shake flask cultivations of strain MGA3, as described by Hakvåg et al. 2019 (submitted for publication), suggesting that the mannitol concentration of the $\mathrm{SWE}_{50}$ medium should be sufficient for growth of strain MGA3. As expected, adding additional mannitol to the $\mathrm{SWE}_{50}$ medium did not support any further growth of the strain (results not shown). As shown in Fig. 4, increasing the mannitol concentration in $\mathrm{SWE}_{25}$ medium ( $\mathrm{SWE}_{25}+$ mannitol) did not affect the growth rate of the cultures but gave rise to an increase in maximum $\mathrm{OD}_{600}$ achieved, suggesting that the mannitol content was the limiting factor for growth. Interestingly, the maximum $\mathrm{OD}_{600}$ reached was even higher than what could be observed for cultures growing on $\mathrm{Man}_{10}$-medium, indicating a synergetic effect on growth by combining the seaweed extract with sufficient available carbon source (here: mannitol). The biological reason for this effect is not known, and a further investigation was not within the scope of this work. In summary, these results indicate a potential of utilizing this raw material as carbon source in cultivations of $B$. methanolicus.

\section{Discussion}

Seaweeds are a potential source of biomolecules for a wide range of applications e.g. bio-active compounds, food and feed supplements and hydrocolloids as well as a raw material 
Fig. 3 Final $\mathrm{OD}_{600}$ of B. methanolicus wild type strain MGA3 cultivated in MVcM medium containing 25 and $50 \%$ $(\mathrm{v} / \mathrm{v})$ extract of seaweed L. digitata (SWE). Extracts were prepared by either acid $(\mathrm{HCl}$ $0.1 \mathrm{M}$ ) or hot water pre-treatment (20 $\mathrm{min}$ and $60 \mathrm{~min}$ ). Growth in medium containing mannitol $\left(10 \mathrm{~g} \mathrm{~L}^{-\mathbf{1}}\right)$ was used as growth control. Cultivations were performed in deep well plates for 20 $24 \mathrm{~h}$. The error bars represent standard deviation (SD) of measured $\mathrm{OD}_{600}$-values from triplicate cultures

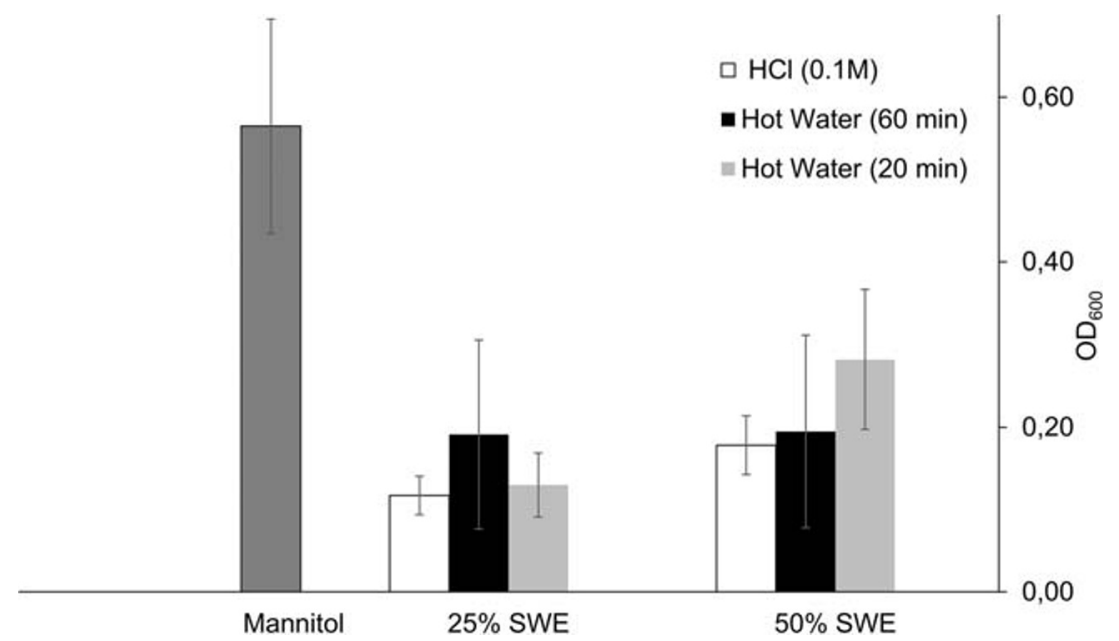

for enzymatic and microbial conversions to chemicals and fuels. To fully utilize the resources, insight into their chemical composition is necessary, including the composition of fractions obtained from the pre-treatments designed to solubilize and extract the relevant components of the material. In this work, concentrations of macro and micronutrients including carbohydrates, protein, minerals and heavy metals of two batches of $L$. digitata were analysed, before and after minimal pre-treatments designed to extract soluble polysaccharides from this biomass.

The analysis of L. digitata in the batches LAM 50 and LAM 50/20 and in the studies by Adams et al. (2011) and Schiener et al. (2015) showed that variations in chemical composition occurred. These variations may be due to the fluctuations in salinity, light exposure, water temperature and nutrient availability that occur between seasons and harvesting sites. In more detail, ash content of brown seaweed can be up to $50 \%$ of its dry matter (Moss 1952), reaching the maximum in the winter period. Likewise, maximum protein content is in winter when the seaweed accumulates nitrogen for tissue growth over the summer. In contrast, maximum amount of storage carbohydrates including laminarin and mannitol have been found over the summer, while these carbohydrates are utilized as an energy source during winter (Adams et al. 2011; Schiener et al. 2015). The seasonal variation in alginate content of the seaweed is less pronounced compared to the variation of other compounds but the proportion of M-blocks,

Table 9 Maximum $\mathrm{OD}_{600}$ obtained in shake flask cultivations for B. methanolicus wild type strain MGA3 in MVcM medium containing either mannitol or SWE (20-min hot water pre-treated). Standard deviation of measured values from triplicate cultures is indicated

\begin{tabular}{llllll}
\hline Mannitol concentration & $\sim 4.5 \mathrm{~g} \mathrm{~L}^{-1}$ & & & $\sim 2.5 \mathrm{~g} \mathrm{~L}^{-1}$ & \\
\cline { 2 - 3 } \cline { 5 - 6 } Medium & $\mathrm{Man}_{4.5}$ & $\mathrm{SWE}_{50}$ & & $\mathrm{Man}_{2.5}$ & $\mathrm{SWE}_{25}$ \\
\hline Maximum $\mathrm{OD}_{600}$ & $3.6 \pm 0.2$ & $2.0 \pm 0.2$ & & $2.27 \pm 0.12$ & $2.0 \pm 0.2$ \\
\hline
\end{tabular}

G-blocks and MG blocks undergoes some changes over the year, which can result in variation in $\mathrm{M} / \mathrm{G}$ ratio (Honya et al. 1993). This may also explain the variation in $M / G$ ratio in published data. The lower variation in alginate content may be explained by the role of this polymer as structural support to the cell wall, where alginic acid chains interact with alkaline metals (D'Este et al. 2017).

Minerals and trace elements of the seaweed are analysed not only to have insight into the chemical composition of the seaweed but also to evaluate the possibility of utilizing the biomass in food and feed applications. According to French recommendation, on use of seaweed for human consumption (Mabeau and Fleurence 1993; Besada et al. 2009), the limits for heavy metals concentration in edible seaweeds are $\mathrm{Cd}<$ $0.0005 \mathrm{mg} \mathrm{g}^{-1} \mathrm{DW}, \mathrm{Hg}<0.0001 \mathrm{mg} \mathrm{g}^{-1} \mathrm{DW}$ and inorganic

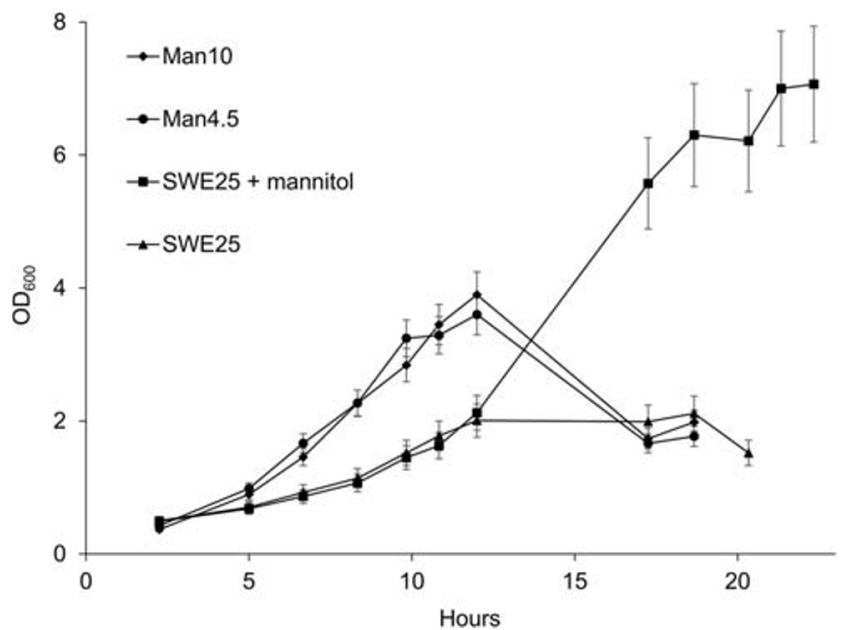

Fig. 4 Growth of B. methanolicus wild type strain MGA3 on minimal medium with mannitol (Man, 10 and $4.5 \mathrm{~g} \mathrm{~L}^{-\mathbf{1}}$ ), or $25 \%(\mathrm{v} / \mathrm{v})$ extract of the seaweed $L$. digitata $\left(\mathrm{SWE}_{25}\right)$. Extracts were prepared by hot water pre-treatment for $20 \mathrm{~min}$. Cultivations with seaweed extracts were performed with and without additional mannitol added to the culture medium, corresponding to total mannitol content in the cultures of 8.1 and $2.5 \mathrm{~g} \mathrm{~L}^{-1}$, respectively. Average standard deviation of measured $\mathrm{OD}_{600^{-}}$ values of triplicate cultures is indicated 
arsenic $<0.003 \mathrm{mg} \mathrm{g}^{-1} \mathrm{DW}$. For the three metals, only arsenic exceeded the recommended value, but it should be emphasized that the analysis made here on $L$. digitata included both organic and inorganic As.

Two pre-treatment methods, mild acid and hot water (20 and $60 \mathrm{~min}$ ) were used to solubilize a mixture of carbohydrates. The carbohydrate extraction yields were calculated to be $12.4 \%$, $20.1 \%$ and $19.7 \%$, respectively, for acid, 20-min and 60-min hot water pre-treatments. The carbohydrate analysis made showed that all pre-treatments led to loss of total carbohydrates, corresponding to $31.8 \%$ of the carbohydrates after acid treatment and $28.7 \%$ and $38.6 \%$ of the carbohydrates, respectively, after 20-min and 60-min hot water pre-treatments.

By considering the amount of glucose, uronic acids and fucose as an indication of the respective concentration of laminarin (the soluble seaweed glucan), alginate and fucoidan, in the soluble extract, it was shown that hot water pre-treatment contained a mixture of the three polysaccharides (laminarin, alginate, and fucoidan), while alginate remained in the insoluble fraction after acid pre-treatment. This is because alginate is naturally available in the cell wall of the seaweed in the form of alginate salts, where addition of $\mathrm{HCl}$ results in conversion of alginate salts into water insoluble alginic acid, which hence remains in the insoluble fraction. Fractionation of polysaccharides in the extracts using size exclusion chromatography (Table 5) showed that neutral sugars and uronic acids were distributed between fractions and no peak represented a single polysaccharide species. Polysaccharides interaction with salts, minerals and proteins (Chizhov et al. 1998; Dianawati et al. 2012) could be a possible reason for this.

By looking at the efficiency of the pre-treatment methods in solubilizing carbohydrates, hot water pre-treatments were the most efficient methods in solubilizing laminarin, alginate and fucoidan. Around 17\% of the total glucans, $7 \%$ of alginate, and $49 \%$ of fucoidan were solubilized during hot water pre-treatments. The acid pre-treatment was less efficient, with extraction yields of glucans, alginate and fucoidan calculated to be $13.7 \%, 1.1 \%$ and $30.2 \%$, respectively (Fig. 2 b). The non-extracted insoluble glucan fraction may also contain crystalline cellulose, which for example is reported by Kloareg and Quatrano (1988) to be present in the cell wall of brown seaweed at very low levels. Salmeán et al. (2017) has also recently reported that the crystalline glucans could consist of insoluble mixed linkage glucans in brown algae cells. These polysaccharides may be present in the insoluble fraction obtained after the extraction, while the storage polysaccharide laminarin is at least partly solubilized during the extraction of the biomass. Two types of polymeric laminarin chains are found in many species, M-chains terminated by the sugar alcohol mannitol and G-chains terminated by a reducing glucose. M-chains are more abundant than $\mathrm{G}$ chains in $L$. digitata where the ratio of $\mathrm{M}$ and $\mathrm{G}$ chain was determined to be as high as 3:1 (Read et al. 1996), which partly explains presence of mannitol in the intermediate sized fractions after size exclusion chromatography. Laminarin has an average molecular weight of $2000-5000 \mathrm{kDa}$ (and even up to $7000 \mathrm{kDa}$ ) that corresponds roughly to DP of $\sim 20-30$ (up to 40) glucose units (Spicer et al. 2017), which fits with the increased amounts of glucose in the hydrolysates in these molecular weight fractions after size exclusion chromatography.

The low molecular weight of alginate in this study could be due to the existence of short chain alginate in the seaweed or degradation of alginate because of the pre-treatment conditions or leaving the long chain polymers in the insoluble fractions. Applying alkaline extraction, however, resulted in extracting pure alginate from the insoluble fraction that remained after acid pre-treatment. The $\mathrm{M} / \mathrm{G}$ ratio of the extracted alginate was however higher than the native $M / G$ ratio, which may be unfavourable as a high amount of guluronic acids is often required in applications (Jönsson et al. 2020).

The extracts were subsequently tested if they could support growth of the thermophilic bacteria $R$. marinus and B. methanolicus. These two bacterial strains produce metabolites with application potential and finding a sustainable growth source is thus of interest for their potential as cell factories utilizing seaweed-based feedstocks. $R$. marinus can produce carotenoids and exopolysaccharides (Sardari et al. 2017; Ron et al. 2018), while $B$. methanolicus strains are potential producers of cadaverine, $\gamma$-aminobutyric acid (GABA) and amino acids (Brautaset et al. 2010; Irla et al. 2014; Naerdal et al. 2015).

In this work, both $R$. marinus and B. methanolicus were shown to utilize extracts of the seaweed $L$. digitata for growth. However, inhibition of growth could be detected with increasing concentrations of the extracts. The inhibitory effect could be due to increased salt concentrations or the presence of inhibitory compounds such as phenolic compounds, as also suggested by Hakvåg et al. 2019 (submitted for publication). On the other hand, an additive effect (higher biomass formation) was observed for cultures of B. methanolicus MGA3 cultivated with $\mathrm{SWE}_{25}$ medium supplemented with extra mannitol compared with when cultivated with mannitol alone. This additive effect indicates that growth-promoting compounds, other than the carbon source, are also present in the extracts, suggesting a possible use of the extracts as medium supplements. The use of brown seaweeds as additives in fermentation medium as a source of minerals and micronutrients has earlier been described (Sharma et al. 2018) and may thus be an attractive source for future cultivation media supporting growth of various microorganisms.

\section{Conclusion}

This study presents three objectives: to experimentally determine the chemical composition of $L$. digitata with focus on detailed carbohydrate composition and investigation of 
minimal pre-treatment methods for extraction of soluble polysaccharides in terms of composition and yield to allow growth of microorganisms with application potential in future biorefineries. Based on the low extraction of alginate by mild acid, an additional alkaline step was added to solubilize this polymer. The results revealed that 20-min hot water pretreatment was the most efficient method for extraction. Extraction from hot water pre-treatments $(20 \mathrm{~min}$ and $60 \mathrm{~min}$ ) resulted in solubilization of a mixture of polysaccharides including neutral sugars and alginate, whereas in acid pre-treatment, alginate remained in the solid remaining residues. Size exclusion chromatography profile of the extracts had several overlapping peaks in the range of the column. Each peak was composed of almost all neutral sugars and uronic acids, except mannitol, which was not presented in high molecular weight fractions of the extracts from hot water pre-treatments. This might be due to interaction of polysaccharides with each other and with external ions including salts and protein available in the extracts. The elemental analysis of the extract showed that the extract from acid pre-treatment contained significant amount of calcium. Since in acid pretreatment alginate remained in solid remaining residues, an alkaline extraction process was used for the extraction of alginate from this fraction followed by precipitation using $\mathrm{CaCl}_{2}$, which resulted in extracting pure alginate. According to growth data, $R$. marinus can utilize the extract from acid pre-treatment while growth was less significant in the presence of the extracts from hot water pre-treatment. The hot water extract, however, supported growth of B. methanolicus and contained high concentration of mannitol. This not only proves the possibility to use minimal pre-treatment to create nutrients for microbial growth but also shows the importance in selecting the conditions for the targeted bacteria.

Funding information Open access funding provided by Lund University. The authors received financial support for the projects Thermofactories, (Era-net MBT1, grant agreement No 604814), MacroVal (the Swedish research council Formas, grant 2015-769), Marine food resources for new markets (Formas, grant 2018-01863), Macro cascade (Bio-Based Industries Joint Undertaking under EU Horizon 2020, grant agreement No 720755), the Novo Nordisk foundation (grant agreement No NNF18OC00349792) and ProSeaFood, (Era-net SusFood2, grant agreement No 727473).

Open Access This article is licensed under a Creative Commons Attribution 4.0 International License, which permits use, sharing, adaptation, distribution and reproduction in any medium or format, as long as you give appropriate credit to the original author(s) and the source, provide a link to the Creative Commons licence, and indicate if changes were made. The images or other third party material in this article are included in the article's Creative Commons licence, unless indicated otherwise in a credit line to the material. If material is not included in the article's Creative Commons licence and your intended use is not permitted by statutory regulation or exceeds the permitted use, you will need to obtain permission directly from the copyright holder. To view a copy of this licence, visit http://creativecommons.org/licenses/by/4.0/.

\section{References}

Adams JMM, Ross AB, Anastasakis K, Hodgson EM, Gallagher JA, Jones JM, Donnison IS (2011) Seasonal variation in the chemical composition of the bioenergy feedstock Laminaria digitata for thermochemical conversion. Bioresour Technol 102:226-234

Alfredsson GA, Kristjansson JK, Hjörleifsdottir S, Stetter KO (1988)Rhodothermus marinus, gen. nov., sp. nov., a thermophilic, halophilic bacterium from submarine hot springs in Iceland. J Gen Microbiol 134:299-306

Angell AR, Mata L, de Nys R, Paul NA (2016) The protein content of seaweeds: a universal nitrogen-to-protein conversion factor of five. J Appl Phycol 28:511-524

Arfman N, Dijkhuizen L, Kirchhof G, Ludwig W, Schleifer K-H, Bulygina ES, Chumakov KM, Govorukhina NI, Trotsenko YA, White D, Sharp RJ (1992)Bacillus methanolicus sp. nov., a new species of thermotolerant, methanol-utilizing, endospore-forming bacteria. Int J Syst Evol Microbiol 42:439-445

Bedoux G, Hardouin K, Burlot AS, Bourgougnon N (2014) Chapter twelve - bioactive components from seaweeds: cosmetic applications and future development. Adv Bot Res 71:345-378

Besada V, Andrade JM, Schultze F, González JJ (2009) Heavy metals in edible seaweeds commercialised for human consumption. J Mar Syst 75:305-313

Bjornsdottir SH, Blondal T, Hreggvidsson GO, Eggertsson G, Petursdottir S, Hjorleifsdottir S, Thorbjarnardottir SH, Kristjansson JK (2006)Rhodothermus marinus: physiology and molecular biology. Extremophiles 10:1-16

Blücher A, Karlsson EN, Holst O (2000)Substrate-dependent production and some properties of a thermostable, $\alpha$-galactosidase from Rhodothermus marinus. Biotechnol Lett 22:663-669

Brautaset T, Jakobsen MØM, Flickinger MC, Valla S, Ellingsen TE (2004)Plasmid-dependent methylotrophy in thermotolerant Bacillus methanolicus. J Bacteriol 186:1229-1238

Brautaset T, Jakobsen ØM, Degnes KF, Netzer R, Nærdal I, Krog A, Dillingham R, Flickinger MC, Ellingsen TE (2010)Bacillus methanolicus pyruvate carboxylase and homoserine dehydrogenase I and II and their roles for l-lysine production from methanol at $50^{\circ} \mathrm{C}$. Appl Microbiol Biotechnol 87:951-964

Chen H, Zhou D, Luo G, Zhang S, Chen J (2015) Macroalgae for biofuels production: progress and perspectives. Renew Sust Energ Rev 47:427-437

Chizhov AO, Dell A, Morris HR, Reason AJ, Haslam SM, McDowell RA, Chizhov OS, Usov AI (1998) Structural analysis of laminarans by MALDI and FAB mass spectrometry. Carbohydr Res 310:203-210

D’Este M, Alvarado-Morales M, Ciofalo A, Angelidaki I (2017) Macroalgae Laminaria digitata and Saccharina latissima as potential biomasses for biogas and total phenolics production: focusing on seasonal and spatial variations of the algae. Energy Fuel 31:7166-7175

Devillé C, Damas J, Forget P, Dandrifosse G, Peulen O (2004) Laminarin in the dietary fibre concept. J Sci Food Agric 84:1030-1038

Dianawati D, Mishra V, Shah NP (2012) Role of calcium alginate and mannitol in protecting Bifidobacterium. Appl Environ Microbiol 78: 6914-6921

Fernand F, Israel A, Skjermo J, Wichard T, Timmermans KR, Golberg A (2017) Offshore macroalgae biomass for bioenergy production: environmental aspects, technological achievements and challenges. Renew Sust Energ Rev 75:35-45

Fertah M, Belfkira A, Em D, Taourirte M, Brouillette F (2017) Extraction and characterization of sodium alginate from Moroccan Laminaria digitata brown seaweed. Arab J Chem 10:S3707-S3714

Hannon M, Gimpel J, Tran M, Rasala B, Mayfield S (2010) Biofuels from algae: challenges and potential. Biofuels 1:763-784

Honya M, Kinoshita T, Ishikawa M, Mori H, Nisizawa K (1993) Monthly determination of alginate, $\mathrm{M} / \mathrm{G}$ ratio, mannitol, and minerals in cultivated Laminaria japonica. Nippon Suisan Gakkaishi 59:295-299 
Hreggvidsson GO, Jonsson Wheat Jon O, Bjornsdottir B, Fridjonsson Olafur H, Altenbuchner J, Watzlawick H, Dobruchowska Justyna M, Kamerling Johannis P (2015) Thermostable alginate degrading enzymes and their methods of use. WO Patent WO/2015/104723

Irla M, Neshat A, Winkler A, Albersmeier A, Heggeset TMB, Brautaset T, Kalinowski J, Wendisch VF, Rückert C (2014) Complete genome sequence of Bacillus methanolicus MGA3, a thermotolerant amino acid producing methylotroph. J Biotechnol 188:110-111

Jakobsen OM, Benichou A, Flickinger MC, Valla S, Ellingsen TE, Brautaset $\mathrm{T}$ (2006) Upregulated transcription of plasmid and chromosomal ribulose monophosphate pathway genes is critical for methanol assimilation rate and methanol tolerance in the methylotrophic bacterium Bacillus methanolicus. J Bacteriol 188:3063-3072

John JM, Benjamin S, Philip WD, Patricia H (2014)Macroalgae-derived biofuel: a review of methods of energy extraction from seaweed biomass. Energies 7:194-7222

Jönsson M, Allahgholi L, Sardari RRR, Hreggviðsson GO, Nordberg Karlsson E (2020) Extraction and modification of macroalgal polysaccharides for current and next-generation applications. Molecules 25:930

Kadam SU, Álvarez C, Tiwari BK, O’Donnell CP (2015) Chapter 9 - extraction of biomolecules from seaweeds. In: Tiwari BK, Troy DJ (eds) Seaweed sustainability. Academic Press, San Diego, pp 243-269

Kloareg B, Quatrano R (1988) Structure of the cell walls of marine algae and ecophysiological functions of the matrix polysaccharides. Oceanogr Mar Biol Annu Rev 26:259-315

Komives CF, Cheung LY-Y, Pluschkell SB, Flickinger MC (2005) Growth of Bacillus methanolicus in seawater-based media. J Ind Microbiol Biotechnol 32:61-66

Lee KY, Mooney DJ (2012) Alginate: properties and biomedical applications. Prog Polym Sci 37:106-126

López MG, Irla M, Brito LF, Wendisch VF (2019) Characterization of Darabitol as newly discovered carbon source of Bacillus methanolicus. Front Microbiol 10:1725-1725

Mabeau S, Fleurence J (1993) Seaweed in food products: biochemical and nutritional aspects. Trends Food Sci Technol 4:103-107

Machu L, Misurcova L, Vavra Ambrozova J, Orsavova J, Mlcek J, Sochor J, Jurikova T (2015) Phenolic content and antioxidant capacity in algal food products. Molecules 20:1118

Mæhre HK, Malde MK, Eilertsen K-E, Elvevoll EO (2014) Characterization of protein, lipid and mineral contents in common Norwegian seaweeds and evaluation of their potential as food and feed. J Sci Food Agric 94:3281-3290

Martins S, Mussatto SI, Martínez-Avila G, Montañez-Saenz J, Aguilar CN, Teixeira JA (2011) Bioactive phenolic compounds: production and extraction by solid-state fermentation. A review. Biotechnol Adv 29:365-373

McHugh DJ (1987) Production and utilization of products from commercial seaweeds. Food and Agriculture Organization of the United Nations, Rome

Moss B (1952) Variations in chemical composition during the development of Himanthalia elongata (L.) S. F. Gray. J Mar Biol Assoc UK 31:29-34

Naerdal I, Pfeifenschneider J, Brautaset T, Wendisch VF (2015)Methanolbased cadaverine production by genetically engineered Bacillus methanolicus strains. Microb Biotechnol 8:342-350

Obata O, Akunna JC, Walker G (2015) Hydrolytic effects of acid and enzymatic pre-treatment on the anaerobic biodegradability of Ascophyllum nodosum and Laminaria digitata species of brown seaweed. Biomass Bioenergy 80:140-146

Papageorgiou SK, Kouvelos EP, Katsaros FK (2008) Calcium alginate beads from Laminaria digitata for the removal of $\mathrm{Cu}^{+2}$ and $\mathrm{Cd}^{+2}$ from dilute aqueous metal solutions. Desalination 224:293-306

Qin Y (2008) Alginate fibres: an overview of the production processes and applications in wound management. Polym Int 57:171-180

Read SM, Currie G, Bacic A (1996) Analysis of the structural heterogeneity of laminarin by electrospray-ionisation-mass spectrometry. Carbohydr Res 281:187-201
Rioux LE, Turgeon SL, Beaulieu M (2007) Characterization of polysaccharides extracted from brown seaweeds. Carbohydr Polym 69:530-537

Ron EYC, Plaza M, Kristjansdottir T, Sardari RRR, Bjornsdottir SH, Gudmundsson S, Hreggvidsson GO, Turner C, van Niel EWJ, Karlsson EN (2018) Characterization of carotenoids in Rhodothermus marinus. Microbiologyopen 7:e00536

Rupérez P (2002) Mineral content of edible marine seaweeds. Food Chem 79:23-26

Saha BC, Racine FM (2011) Biotechnological production of mannitol and its applications. Appl Microbiol Biotechnol 89:879-891

Salmeán AA, Duffieux D, Harholt J, Qin F, Michel G, Czjzek M, Willats WGT, Hervé C (2017) Insoluble $(1 \rightarrow 3),(1 \rightarrow 4)-\beta$-D-glucan is a component of cell walls in brown algae (Phaeophyceae) and is masked by alginates in tissues. Sci Rep 7:2880

Sardari RRR, Karlsson EN (2018) Marine poly- and oligosaccharides as prebiotics. J Agric Food Chem 66:11544-11549

Sardari RRR, Kulcinskaja E, Ron EYC, Björnsdóttir S, Friðjónsson ÓH, Hreggviðsson GÓ, Karlsson EN (2017) Evaluation of the production of exopolysaccharides by two strains of the thermophilic bacterium Rhodothermus marinus. Carbohydr Polym 156:1-8

Schendel FJ, Bremmon CE, Flickinger MC, Guettler M, Hanson RS (1990)L-lysine production at $50^{\circ} \mathrm{C}$ by mutants of a newly isolated and characterized methylotrophic Bacillus sp. Appl Environ Microbiol 56:963

Schiener P, Black KD, Stanley MS, Green DH (2015) The seasonal variation in the chemical composition of the kelp species Laminaria digitata, Laminaria hyperborea, Saccharina latissima and Alaria esculenta. J Appl Phycol 27:363-373

Sharma S, Hansen LD, Hansen JØ, Mydland LT, Horn SJ, Øverland M, Eijsink VGH, Vuoristo KS (2018) Microbial protein produced from brown seaweed and spruce wood as a feed ingredient. J Agric Food Chem 66:8328-8335

Sluiter A, Hames B, Ruiz R, Scarlata C, Sluiter J, Templeton D, Crocker D (2008a) Determination of ash in biomass. Laboratory NRE, Golden NREL/TP-510-42622

Sluiter A, Hames B, Ruiz R, Scarlata C, Sluiter J, Templeton D, Crocker D (2008b) Determination of structural carbohydrates and lignin in biomass. Laboratory NRE, Golden, Colorado. NREL/TP-510-42618

Spicer SE, Adams JMM, Thomas DS, Gallagher JA, Winters AL (2017) Novel rapid method for the characterisation of polymeric sugars from macroalgae. J Appl Phycol 29:1507-1513

Stålbrand H, Siika-aho M, Tenkanen M, Viikari L (1993) Purification and characterization of two $\beta$-mannanases from Trichoderma reesei. J Biotechnol 29:229-242

Sterner M, Edlund U (2016) Multicomponent fractionation of Saccharina latissima brown algae using chelating salt solutions. J Appl Phycol 28:2561-2574

Thorsen MK, Woodward S, McKenzie BM (2010) Kelp (Laminaria digitata) increases germination and affects rooting and plant vigour in crops and native plants from an arable grassland in the Outer Hebrides, Scotland. J Coast Conserv 14:239-247

Vauchel P, Arhaliass A, Legrand J, Kaas R, Baron R (2008a) Decrease in dynamic viscosity and average molecular weight of alginate from Laminaria digitata during alkaline extraction. J Phycol 44:515-517

Vauchel P, Kaas R, Arhaliass A, Baron R, Legrand J (2008b) A new process for extracting alginates from Laminaria digitata: reactive extrusion. Food Bioprocess Technol 1:297-300

Wu J, Zhao X, Ren L, Xue Y, Li C, Yu G, Guan H (2014) Determination of M/G ratio of propylene glycol alginate sodium sulfate by HPLC with pre-column derivatization. Carbohydr Polym 104:23-28

Publisher's note Springer Nature remains neutral with regard to jurisdictional claims in published maps and institutional affiliations. 